Article

\title{
New Anti-Inflammatory Aporphine and Lignan Derivatives from the Root Wood of Hernandia nymphaeifolia
}

\author{
Chuan-Yen Wei ${ }^{1,+}$, Shih-Wei Wang ${ }^{2,+}$, Jin-Wang Ye ${ }^{3}$, Tsong-Long Hwang 4,5,6 $\mathbb{D}$, \\ Ming-Jen Cheng ${ }^{7}$, Ping-Jyun Sung ${ }^{8}(\mathbb{D})$, Tsung-Hsien Chang ${ }^{9}(\mathbb{D})$ and Jih-Jung Chen ${ }^{10,11, *}$
}

1 Department of General Surgery, Taitung MacKay Memorial Hospital, Taitung City 950, Taiwan; lpshop@gmail.com

2 Department of Medicine, Mackay Medical College, New Taipei City 252, Taiwan; shihwei@mmc.edu.tw

3 Graduate Institute of Pharmaceutical Technology, Tajen University, Pingtung 907, Taiwan; jjc8506674@gmail.com

4 Graduate Institute of Natural Products, School of Traditional Chinese Medicine, College of Medicine, Chang Gung University, Taoyuan 333, Taiwan; htl@mail.cgu.edu.tw

5 Research Center for Chinese Herbal Medicine, Research Center for Food and Cosmetic Safety, Graduate Institute of Health Industry Technology, College of Human Ecology, Chang Gung University of Science and Technology, Taoyuan 333, Taiwan

6 Department of Anesthesiology, Chang Gung Memorial Hospital, Taoyuan 333, Taiwan

7 Bioresource Collection and Research Center (BCRC), Food Industry Research and Development Institute (FIRDI), Hsinchu 300, Taiwan; cmj@firdi.org.tw

8 National Museum of Marine Biology and Aquarium, Pingtung 944, Taiwan; pjsung@nmmba.gov.tw

9 Department of Medical Education and Research, Kaohsiung Veterans General Hospital, Kaohsiung 813, Taiwan; changth@vghks.gov.tw

10 Faculty of Pharmacy, School of Pharmaceutical Sciences, National Yang-Ming University, Taipei 112, Taiwan

11 Department of Medical Research, China Medical University Hospital, China Medical University, Taichung 404, Taiwan

* Correspondence: chenjj@ym.edu.tw; Tel.: +886-2-2826-7195

+ Authors have contributed equally in this manuscript.

Received: 15 August 2018; Accepted: 1 September 2018; Published: 7 September 2018

\begin{abstract}
A new aporphine, 3-hydroxyhernandonine (1) and a new lignin, 4'-O-demethyl-7-Omethyldehydropodophyllotoxin (2), have been isolated from the root wood of Hernanadia nymphaeifolia, together with thirteen known compounds (3-15). The structures of these compounds were determined through mass spectrometry (MS) and spectroscopic analyses. The known isolate, 2-O-methyl-7-oxolaetine (3), was first isolated from natural sources. Among the isolated compounds, 3-hydroxyhernandonine (1), 4'-O-demethyl-7-O-methyldehydropodophyllotoxin (2), hernandonine (4), oxohernangerine (5), and oxohernagine (6) displayed inhibition $\left(\mathrm{IC}_{50}\right.$ values $\leq 5.72 \mu \mathrm{g} / \mathrm{mL}$ ) of superoxide anion production by human neutrophils in response to formyl-L-methionyl-L-leucyl-L-phenylalanine/cytochalasin B (fMLP/CB). In addition, 3-hydroxyhernandonine (1), 4'-O-demethyl-7-O-methyldehydropodophyllotoxin (2), oxohernangerine (5), and oxohernagine (6) suppressed $\mathrm{fMLP} / \mathrm{CB}$-induced elastase release with $\mathrm{IC}_{50}$ values $\leq 5.40$ $\mu \mathrm{g} / \mathrm{mL}$.
\end{abstract}

Keywords: Hernanadia nymphaeifolia; Hernandiaceae; root wood; structure elucidation; aporphine; lignan; anti-inflammatory activity 


\section{Introduction}

Hernanadia nymphaeifolia (Presl) Kubitzki (Hernandiaceae) is an evergreen tree that is distributed in the tropical island shores of the Indian and western Pacific Oceans [1]. Its seed is used as a cathartic [2]. Various aporphines [3-7], isoquinolones [4,5], lignans [4,7,8], benzylisoquinoline [5], steroids [7], and their derivatives were isolated from this species in past studies. Many of these isolates display cytotoxic [4,5,8], vasorelaxing [6], antioxidant [6], and antiplatelet aggregation [7] activities.

The extensive or inappropriate activation of neutrophils leads to many inflammatory disorders such as chronic obstructive pulmonary disease (COPD), ischemia-reperfusion injury, asthma, rheumatoid arthritis, and metabolic diseases $[9,10]$. In response to various stimuli, activated neutrophils secrete a series of cytotoxins, such as granule proteases, bioactive lipids, and superoxide anion $\left(\mathrm{O}_{2}{ }^{\bullet-}\right)$, a precursor of other reactive oxygen species (ROS) [10-12]. The inhibition of the abnormal activation of neutrophils by medicines has been recommended as a way to improve inflammatory diseases. In our researches on the anti-inflammatory constituents of Formosan plants, numerous species have been screened for anti-inflammatory activity, and H. nymphaeifolia has been found to be an active species. A new aporphine, 3-hydroxyhernandonine (1), a new lignin, 4'-O-demethyl-7-O-methyldehydropodophyllotoxin (2), and thirteen known compounds (3-15) have been isolated and determined from the root wood of Hernanadia nymphaeifolia, and their structures are described in Figure 1.

This article describes the structural elucidation of new compounds $\mathbf{1}$ and $\mathbf{2}$ and the inhibitory effects of all isolates on elastase release and superoxide generation by human neutrophils.<smiles>O=C1OCOc2c3c1ccc2c1c2ccnc1c3=C1OCOC1=C2O</smiles><smiles>[R20]Oc1ccc2c(c1[R])-c1c([R20])c([R20])cc3ccnc(c13)C2=O</smiles>

$3 \mathrm{R}_{1}=\mathrm{R}_{2}=\mathrm{CH}_{3}, \mathrm{R}_{3}+\mathrm{R}_{4}=\mathrm{CH}_{2}$

$4 \mathrm{R}_{1}+\mathrm{R}_{2}=\mathrm{R}_{3}+\mathrm{R}_{4}=\mathrm{CH}_{2}$

$5 \mathrm{R}_{1}+\mathrm{R}_{2}=\mathrm{CH}_{2}, \mathrm{R}_{3}=\mathrm{H}, \mathrm{R}_{4}=\mathrm{CH}_{3}$

$6 \mathrm{R}_{1}=\mathrm{R}_{2}=\mathrm{R}_{4}=\mathrm{CH}_{3}, \mathrm{R}_{3}=\mathrm{H}$

$7 \mathrm{R}_{1}=\mathrm{R}_{2}=\mathrm{R}_{3}=\mathrm{CH}_{3}, \mathrm{R}_{4}=\mathrm{H}$<smiles>COc1cc(-c2c3c(c(OC)c4cc5c(cc24)OCO5)C(=O)OC3)cc(OC)c1O</smiles>

2<smiles>COc1cc([C@H]2c3cc4c(cc3C[C@H]3COC(=O)[C@H]23)OCO4)cc(OC)c1OC</smiles>

8

Figure 1. Cont. 
<smiles>COc1cc(-c2c3c(c(O)c4cc5c(cc24)OCO5)C(=O)OC3)cc(OC)c1OC</smiles>

9<smiles>COc1cc(C[C@H]2C(=O)OC[C@H]2Cc2ccc3c(c2)OCO3)cc(OC)c1OC</smiles>

10<smiles>COc1cc(/C=C/C(=O)NCCc2ccc(O)c(OC)c2)ccc1O</smiles>

11<smiles>CC[C@H](CC[C@@H](C)C1CCC2C3CCC4=CC(=O)CC[C@]4(C)C3CCC21C)C(C)C</smiles><smiles>CC[C@H](CC[C@@H](C)C1CCC2C3C[C@H](O)C4=CC(=O)CC[C@]4(C)C3CC[C@@]21C)C(C)C</smiles>

Figure 1. The chemical structures of compounds 1-15 isolated from H. nymphaeifolia.

\section{Results and Discussion}

\subsection{Isolation and Structural Elucidation}

Chromatographic purification of the $\mathrm{CH}_{2} \mathrm{Cl}_{2}$-soluble fraction of a $\mathrm{MeOH}$ extract of root wood of $H$. nymphaeifolia through a silica gel column, medium pressure liquid chromatography (MPLC), and preparative thin-layer chromatography (TLC) yielded two new (1 and 2 ) and thirteen known compounds (3-15) (Figure 1).

The aporphine, 3-hydroxyhernandonine (1), was obtained as yellow needles. The electrospray ionization mass spectrometry (ESI-MS) (Figure S1) afford the quasi-molecular ion $[\mathrm{M}+\mathrm{Na}]^{+}$at $m / z$ 358 , implying a molecular formula of $\mathrm{C}_{18} \mathrm{H}_{9} \mathrm{NO}_{6} \mathrm{Na}$, which was confirmed by the high-resolution 
(HR)-ESI-MS $\left(m / z 358.0325[\mathrm{M}+\mathrm{Na}]^{+}\right.$, calcd 358.0328) (- $\left.0.84 \mathrm{ppm}\right)$ (Figure S2) and by the ${ }^{13} \mathrm{C}-$, ${ }^{1} \mathrm{H}-$, and distortionless enhancement by polarization transfer (DEPT) NMR data. IR absorptions for $\mathrm{OH}\left(3439 \mathrm{~cm}^{-1}\right)$ and conjugated carbonyl $\left(1646 \mathrm{~cm}^{-1}\right)$ functions were observed. The ${ }^{1} \mathrm{H}-\mathrm{NMR}$ spectrum (Figure S3) of 1 showed the presence of a hydroxy group at $\delta_{\mathrm{H}} 6.52\left(1 \mathrm{H}, \mathrm{s}, \mathrm{D}_{2} \mathrm{O}\right.$ exchangeable, $\mathrm{OH}-3)$, two methylenedioxy groups at $\delta_{\mathrm{H}} 6.20\left(2 \mathrm{H}, \mathrm{s}, \mathrm{OCH}_{2} \mathrm{O}-10,11\right)$ and $6.28\left(2 \mathrm{H}, \mathrm{s}, \mathrm{OCH}_{2} \mathrm{O}-1,2\right)$, and two pairs of AB-doublets at $\delta_{\mathrm{H}} 7.08(1 \mathrm{H}, \mathrm{d}, J=8.5 \mathrm{~Hz}, \mathrm{H}-9), 8.10(1 \mathrm{H}, \mathrm{d}, J=5.0 \mathrm{~Hz}, \mathrm{H}-4), 8.28$ $(1 \mathrm{H}, \mathrm{d}, J=8.5 \mathrm{~Hz}, \mathrm{H}-8)$, and $8.88(1 \mathrm{H}, \mathrm{d}, J=5.0 \mathrm{~Hz}, \mathrm{H}-5)$. The ${ }^{1} \mathrm{H}-$ and ${ }^{13} \mathrm{C}-\mathrm{NMR}$ (Figure S4) data of 1 were similar to those of hernandonine [13,14], except that the 3-hydroxy group $\left[\delta_{\mathrm{H}} 6.52\left(1 \mathrm{H}, \mathrm{s}, \mathrm{D}_{2} \mathrm{O}\right.\right.$ exchangeable)] of 1 replaced $\mathrm{H}-3$ of hernandonine [13,14]. This was supported by HMBC correlations between $\mathrm{OH}-3\left(\delta_{\mathrm{H}} 6.52\right)$ and $\mathrm{C}-2\left(\delta_{\mathrm{C}} 139.2\right)$, as well as between $\mathrm{C}-3\left(\delta_{\mathrm{C}} 148.4\right)$, and C-3a $\left(\delta_{\mathrm{C}} 123.9\right)$. The full assignment of ${ }^{1} \mathrm{H}$ - and ${ }^{13} \mathrm{C}-\mathrm{NMR}$ resonances was supported by DEPT, ${ }^{1} \mathrm{H}-{ }^{1} \mathrm{H}$ COSY (Figure S5), NOESY (Figure 2 and Figure S6), HMBC (Figure 2 and Figure S7), and HSQC (Figure S8) spectral analyses. Based on the above data, the structure of $\mathbf{1}$ was revealed as 3-hydroxyhernandonine.
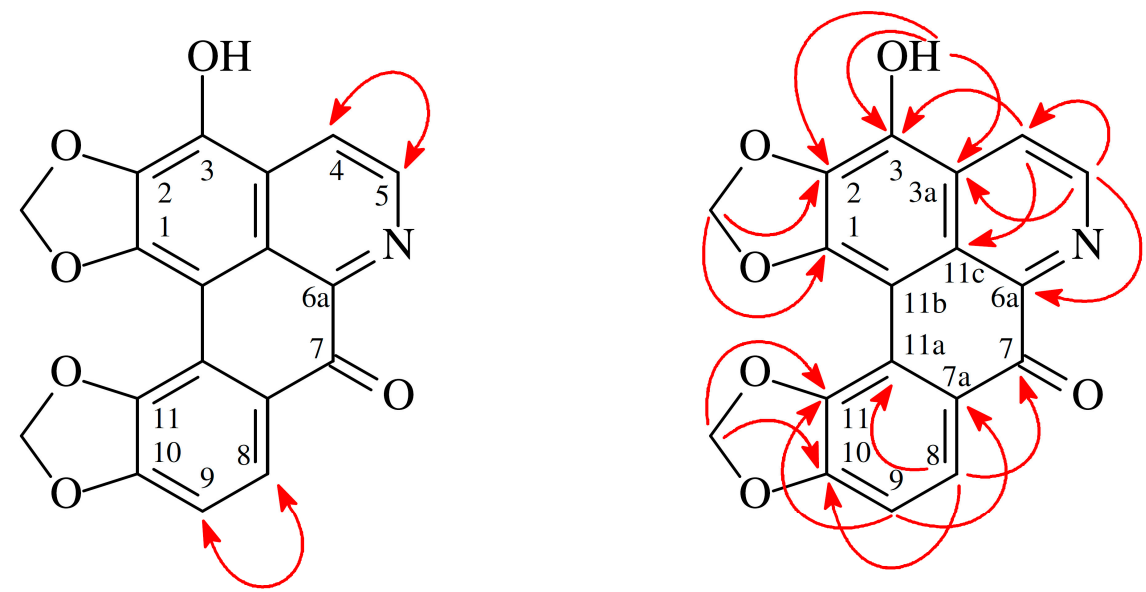

Figure 2. Key NOESY ( ) and HMBC correlations of $\mathbf{1}$

4'-O-Demethyl-7-O-methyldehydropodophyllotoxin (2) was isolated as colorless needles. The ESI-MS (Figure S9) display the sodium adduct ion $[\mathrm{M}+\mathrm{Na}]^{+}$at $m / z 433$, hinting a molecular formula of $\mathrm{C}_{22} \mathrm{H}_{18} \mathrm{O}_{8}$, which was supported by the HR-ESI-MS $\left(m / z 433.0898[\mathrm{M}+\mathrm{Na}]^{+}\right.$, calcd 433.0899) $(-0.23 \mathrm{ppm})$ (Figure S10). The IR spectrum showed the presence of $\mathrm{OH}\left(3452 \mathrm{~cm}^{-1}\right)$ and $\gamma$-lactone carbonyl $\left(1764 \mathrm{~cm}^{-1}\right)$ groups. The ${ }^{1} \mathrm{H}-\mathrm{NMR}$ spectrum (Figure S11) of 2 showed the presence of three methoxy groups at $\delta_{\mathrm{H}} 3.88\left(6 \mathrm{H}, \mathrm{s}, \mathrm{OMe}-3^{\prime}\right.$ and $\left.\mathrm{OMe}-5^{\prime}\right)$ and $4.09(3 \mathrm{H}, \mathrm{s}, \mathrm{OMe}-7)$, a hydroxyl group at $\delta_{\mathrm{H}} 5.65\left(1 \mathrm{H}\right.$, br s, $\mathrm{D}_{2} \mathrm{O}$ exchangeable, $\left.\mathrm{OH}-4^{\prime}\right)$, a methylenedioxy group at $\delta_{\mathrm{H}} 6.09\left(2 \mathrm{H}, \mathrm{s}, \mathrm{OCH}_{2} \mathrm{O}\right)$, a $\gamma$-lactone methylene proton at $5.52(2 \mathrm{H}, \mathrm{s}, \mathrm{H}-9)$, and four aromatic protons at $\delta_{\mathrm{H}} 6.57\left(2 \mathrm{H}, \mathrm{s}, \mathrm{H}-2^{\prime}\right.$ and $\left.\mathrm{H}-6^{\prime}\right), 7.07(1 \mathrm{H}, \mathrm{s}, \mathrm{H}-5)$, and $7.57(1 \mathrm{H}, \mathrm{s}, \mathrm{H}-2)$. The ${ }^{1} \mathrm{H}-$ and ${ }^{13} \mathrm{C}-\mathrm{NMR}$ (Figure S12) data of 2 were similar to those of 4'-O-demethyldehydropodophyllotoxin [15], except that the 7-methoxy groups [ $\delta_{\mathrm{H}} 4.09$ $(3 \mathrm{H}, \mathrm{s}) ; \delta_{\mathrm{C}} 59.9$ (OMe-7)] of 2 replaced the 7-OH group of $4^{\prime}$-O-demethyldehydropodophyllotoxin [15]. This was supported by NOESY correlations between OMe-7 $\left(\delta_{\mathrm{H}} 4.09\right)$ and H-2 $\left(\delta_{\mathrm{H}} 7.57\right)$ and by HMBC correlations between OMe-7 $\left(\delta_{\mathrm{H}} 4.09\right)$ and C-7 $\left(\delta_{\mathrm{C}}\right.$ 148.5). According to the above evidence, the structure of 2 was elucidated as 4'-O-demethyl-7-O-methyldehydropodophyllotoxin. This was further affirmed by the ${ }^{1} \mathrm{H}-{ }^{1} \mathrm{H}-\mathrm{COSY}$ (Figure S13), NOESY (Figure 3 and Figure S14), DEPT, HMBC (Figure 3 and Figure S15), and HSQC (Figure S16) experiments. 

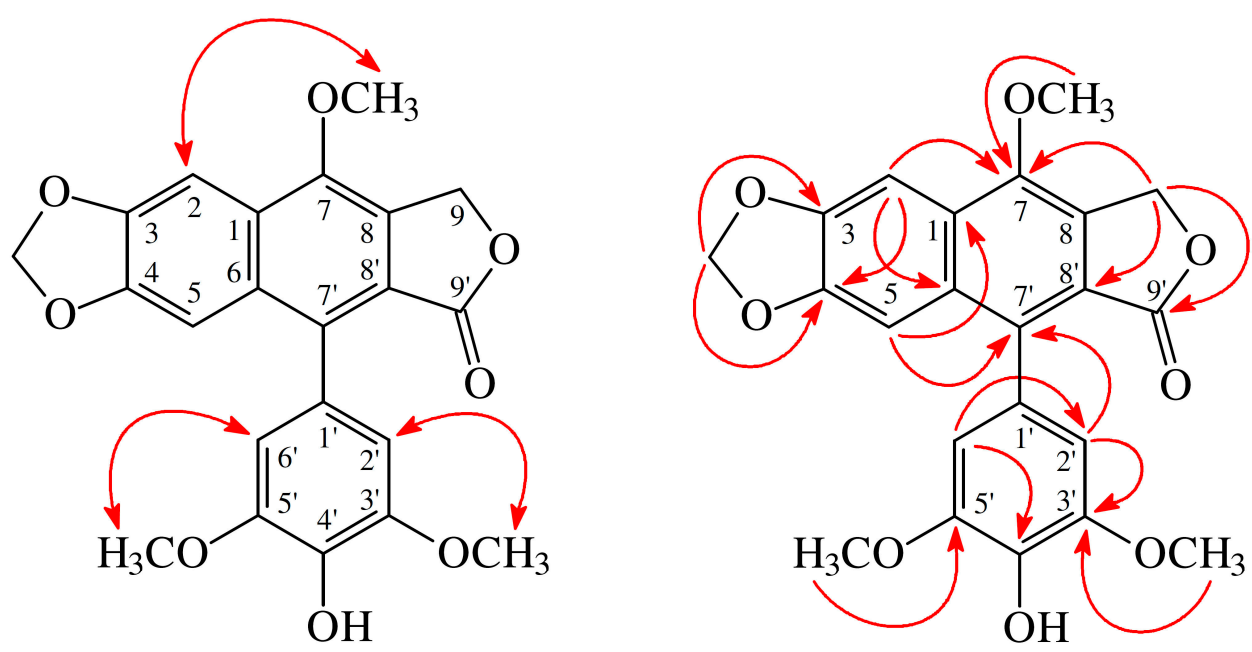

Figure 3. Key NOESY ( $)$ and HMBC $(\longrightarrow)$ correlations of 2.

\subsection{Structure Identification of the Known Isolates}

The known isolated compounds were readily confirmed by a comparison of spectroscopic and physical data (IR, UV, ${ }^{1} \mathrm{H}-\mathrm{NMR}, \mathrm{MS}$, and $[\alpha]_{\mathrm{D}}$ ) with the literature values or corresponding authentic samples, and this included five aporphines, 2-O-methyl-7-oxolaetine (3) [16], hernandonine (4) [13,14], oxohernangerine (5) [17], oxohernagine (6) [17], and 7-oxonorisocorydine (7) [18], three lignans, (-)-deoxypodophyllotoxin (8) [19,20], dehydropodophyllotoxin (9) [20,21], (-)-yatein (10) [20], an amide, $N$-trans-feruloylmethoxytyramine (11) [22], four steroids, a mixture of $\beta$-sitostenone (12) [23] and stigmasta-4,22-dien-3-one (13) [23], and mixture of $6 \beta$-hydroxystigmast-4-en-3-one (14) $[24,25]$ and $6 \beta$-hydroxystigmasta-4,22-dien-3-one (15) [24,25].

\subsection{Biological Studies}

Granule proteases (e.g., cathepsin G, elastase, and proteinase-3) and reactive oxygen species (ROS) (e.g., hydrogen peroxide and superoxide anion $\left(\mathrm{O}_{2}{ }^{\bullet-}\right)$ ) generated by human neutrophils are involved in the pathogenesis of various NMR data [10-12,26]. The activities during neutrophil proinflammatory responses to isolates from the root wood of $H$. nymphaeifolia were assessed by inhibiting fMet-Leu-Phe/cytochalasin $\mathrm{B}$ (fMLP/CB)-induced $\mathrm{O}_{2}{ }^{\bullet-}$ production and elastase release by human neutrophils. The inhibitory activity data on neutrophil proinflammatory responses are shown in Table 1. Diphenyleneiodonium and phenylmethylsulfonyl fluoride were employed as positive controls for $\mathrm{O}_{2}{ }^{\bullet-}$ generation and elastase release, respectively [26]. From the results of our biological assays, the following conclusions can be summarized: (a) 3-hydroxyhernandonine (1), 4'-O-demethyl-7-O-methyldehydropodophyllotoxin (2), hernandonine (4), oxohernangerine (5), and oxohernagine (6) exhibited potent inhibition ( $\mathrm{IC}_{50} \leq 5.72 \mu \mathrm{g} / \mathrm{mL}$ ) of superoxide anion $\left(\mathrm{O}_{2}{ }^{\bullet-}\right)$ generation by human neutrophils in response to fMLP/CB; (b) 3-hydroxyhernandonine (1), 4'-O-demethyl-7-O-methyldehydropodophyllotoxin (2), oxohernangerine (5), and oxohernagine (6) exhibited potent inhibition ( $\mathrm{IC}_{50} \leq 5.40 \mu \mathrm{g} / \mathrm{mL}$ ) of fMLP-induced elastase release; (c) the aporphine alkaloid, 3-hydroxyhernandonine (1) (with a 3-hydroxy group), exhibited more effective inhibition than its analogue, hernandonine (4) (without any substitutant at C-3), against fMLP-induced $\mathrm{O}_{2}{ }^{\bullet-}$ generation and elastase release; (d) oxohernagine (6) (with 10-hydroxy and 11-methoxy groups) exhibited more effective inhibition of fMLP-induced $\mathrm{O}_{2}{ }^{\bullet-}$ generation and elastase release than its analogue, 7-oxonorisocorydine (7) (with 11-hydroxy and 10-methoxy groups; (e) the lignan compound, 4'-O-demethyl-7-O-methyldehydroodophyllotoxin (2) (with 7-methoxy and 4'-hydroxy groups) exhibited more effective inhibition of fMLP-induced $\mathrm{O}_{2}{ }^{\bullet-}$ generation and elastase release than its analogue, dehydropodophyllotoxin (9) (with 7-hydroxy and 4'-methoxy groups); (f) oxohernangerine (5) was the most effective among these compounds, with an $\mathrm{IC}_{50}$ value of $2.65 \pm 0.97 \mu \mathrm{g} / \mathrm{mL}$, against 
fMLP-induced superoxide anion generation; (g) 3-hydroxyhernandonine (1) was the most effective among the isolates, with an $\mathrm{IC}_{50}$ value of $3.93 \pm 0.48 \mu \mathrm{g} / \mathrm{mL}$ against fMLP-induced elastase release.

Table 1. Inhibitory effects of compounds 1-15 from the root wood of H. nymphaeifolia on superoxide radical anion generation and elastase release by human neutrophils in response to fMet-Leu-Phe/cytochalasin B ${ }^{\text {a }}$.

\begin{tabular}{|c|c|c|}
\hline \multirow{2}{*}{ Compounds } & Superoxide anion & Elastase \\
\hline & \multicolumn{2}{|c|}{$\mathrm{IC}_{50}[\mu \mathrm{g} / \mathrm{mL}]^{\mathrm{b}}$ or $(\operatorname{Inh} \%)^{\mathrm{c}}$} \\
\hline 3-Hydroxyhernandonine (1) & $4.09 \pm 0.44^{* * *}$ & $3.93 \pm 0.48^{* * *}$ \\
\hline $\begin{array}{l}4^{\prime} \text {-O-Demethyl-7-O- } \\
\text { methyldehydro-podophyllotoxin (2) }\end{array}$ & $5.72 \pm 0.42^{* * *}$ & $5.40 \pm 0.40^{* * *}$ \\
\hline 2-O-Methyl-7-oxolaetine (3) & $7.37 \pm 0.46^{* * *}$ & $6.82 \pm 0.09^{* * *}$ \\
\hline Hernandonine (4) & $4.41 \pm 0.76^{* * *}$ & $(45.76 \pm 6.92)^{* * *}$ \\
\hline Oxohernangerine (5) & $2.65 \pm 0.97^{* * *}$ & $4.82 \pm 0.39^{* * *}$ \\
\hline Oxohernagine (6) & $2.86 \pm 0.85^{* * *}$ & $4.87 \pm 0.27^{* * *}$ \\
\hline 7-Oxonorisocorydine (7) & $6.62 \pm 0.28^{* * *}$ & $6.58 \pm 0.08^{* * *}$ \\
\hline (-)-Deoxypodophyllotoxin (8) & $(38.95 \pm 4.83)^{* *}$ & $(33.76 \pm 3.82)$ \\
\hline Dehydropodophyllotoxin (9) & $(43.91 \pm 3.86)^{* * *}$ & $9.53 \pm 0.84^{* * *}$ \\
\hline$(-)$-Yatein $(\mathbf{1 0})$ & $(42.36 \pm 3.41) *$ & $(36.74 \pm 3.05)^{* *}$ \\
\hline N-trans-Feruloylmethoxytyramine (11) & $6.26 \pm 0.65^{* * *}$ & $7.03 \pm 0.21^{* * *}$ \\
\hline $\begin{array}{l}\text { Mixture of } \beta \text {-sitostenone (12) and } \\
\text { stigmasta-4,22-dien-3-one (13) }\end{array}$ & $(24.71 \pm 2.67)$ & $(29.15 \pm 2.89)$ \\
\hline $\begin{array}{c}\text { Mixture of } 6 \beta \text {-hydroxystigmast-4-en-3-one (14) and } \\
6 \beta \text {-hydroxystigmasta-4,22-dien-3-one (15) }\end{array}$ & $(16.74 \pm 2.66)^{* *}$ & $7.91 \pm 1.20^{* *}$ \\
\hline Diphenyleneiodonium ${ }^{\mathrm{d}}$ & $0.55 \pm 0.22^{* * *}$ & - \\
\hline Phenylmethylsulfonyl fluoride ${ }^{\mathrm{d}}$ & - & $34.5 \pm 5.3^{* * *}$ \\
\hline
\end{tabular}

a Results are displayed as averages \pm SEM $(n=4) .{ }^{\mathrm{b}}$ Concentration necessary for $50 \%$ inhibition $\left(\mathrm{IC}_{50}\right)$. If $\mathrm{IC}_{50}$ value of tested compound was $<10 \mu \mathrm{g} / \mathrm{mL}$, it was presented as $\mathrm{IC}_{50}[\mu \mathrm{g} / \mathrm{mL}] .{ }^{\mathrm{c}}$ Percentage of inhibition (Inh \%) at $10 \mu \mathrm{g} / \mathrm{mL}$. If $\mathrm{IC}_{50}$ value of tested compound was $\geq 10 \mu \mathrm{g} / \mathrm{mL}$, it was displayed as (Inh \%) at $10 \mu \mathrm{g} / \mathrm{mL}$. ${ }^{d}$ Diphenyleneiodonium and phenylmethylsulfonyl were employed as positive controls for superoxide anion $\left(\mathrm{O}_{2}{ }^{{ }^{--}}\right)$ production and elastase release, respectively. ${ }^{*} p<0.05$ compared with the control. ${ }^{* *} p<0.01$ compared with the control. ${ }^{* * *} p<0.001$ compared with the control.

\section{Experimental Section}

\subsection{General Procedures}

Melting points were determined on a Yanaco micromelting point apparatus and were uncorrected. Ultraviolet (UV) spectra were measured on a Jasco UV-240 spectrophotometer. Optical rotations were acquired using a Jasco DIP-370 polarimeter (Japan Spectroscopic Corporation, Tokyo, Japan) in $\mathrm{CHCl}_{3}$. Infrared (IR) spectra (KBr or neat) were recorded on a Perkin Elmer $2000 \mathrm{FT}-\mathrm{IR}$ spectrometer (Perkin Elmer Corporation, Norwalk, CT, USA). Nuclear magnetic resonance (NMR) spectra, including correlation spectroscopy (COSY), nuclear overhauser effect spectrometry (NOESY), heteronuclear multiple-bond correlation (HMBC) experiments, and heteronuclear single-quantum coherence (HSQC), were obtained using a Varian Inova 500 spectrometer (Varian Inc., Palo Alto, CA, USA) operating at $500 \mathrm{MHz}\left({ }^{1} \mathrm{H}\right)$ and $125 \mathrm{MHz}\left({ }^{13} \mathrm{C}\right)$, respectively, with chemical shifts given in ppm $(\delta)$ and applying tetramethylsilane (TMS) as an internal standard. Electrospray ionization (ESI) and high-resolution electrospray ionization (HRESI)-mass spectra were recorded on a VG Platform Electrospray ESI/MS mass spectrometer (Fison, Villeurbanne, France) or a Bruker APEX II (Bruker, Bremen, Germany). Silica gel (70-230, 230-400 mesh, Merck) was used for column chromatography (CC). Silica gel 60 F-254 (Merck, Darmstadt, Germany) was employed for thin-layer chromatography (TLC) and preparative thin-layer chromatography (PTLC). 


\subsection{Plant Material}

The root wood of Hernanadia nymphaeifolia (Presl) Kubitzki (Hernandiaceae) was collected from Mudan Township, Pingtung County, Taiwan, in August 2008 and identified by Prof. I.-S. Chen. A voucher specimen (Chen 5521) was deposited in the Herbarium of School of Pharmacy, Kaohsiung Medical University, Kaohsiung, Taiwan.

\subsection{Extraction and Isolation}

The dried root wood $(5.1 \mathrm{~kg})$ of $\mathrm{H}$. nymphaeifolia was sliced and extracted three times with $\mathrm{MeOH}$ (40 L each) for three days. The extract was concentrated under reduced pressure at $35^{\circ} \mathrm{C}$, and the residue (386 g) was partitioned between $\mathrm{CH}_{2} \mathrm{Cl}_{2}$ and $\mathrm{H}_{2} \mathrm{O}(1: 1)$ to provide the $\mathrm{CH}_{2} \mathrm{Cl}_{2}$-soluble fraction (fraction A; $87 \mathrm{~g})$. Fraction A (87 g) was purified by CC (3.9 kg of $\mathrm{SiO}_{2}, 70-230$ mesh; $\mathrm{CH}_{2} \mathrm{Cl}_{2} / \mathrm{MeOH}$ gradient) to produce 12 fractions: A1-A12. Fraction A3 (7.5 g) was subjected to CC (340 $\mathrm{g}$ of $\mathrm{SiO}_{2}, 230-400$ mesh; $\mathrm{CH}_{2} \mathrm{Cl}_{2}$ /acetone 30:1-0:1, $900 \mathrm{~mL}$ fractions) to give 11 subfractions: A3-1-A3-11. Fraction A3-4 (340 mg) was purified by MPLC (silica column, $\mathrm{CH}_{2} \mathrm{Cl}_{2}$ /acetone 8:1-0:1) to produce eight subfractions (each $250 \mathrm{~mL}$, A3-4-1-A3-4-8). Fraction A3-4-4 (46 mg) was purified by preparative TLC (silica gel, $\mathrm{CHCl}_{3} / \mathrm{MeOH}, 10: 1$ ) to obtain a mixture of $\beta$-sitostenone (12) and stigmasta-4,22-dien-3-one (13) (8.5 mg). Fraction A5 (6.9 g) was subjected to CC (365 g of $\mathrm{SiO}_{2}, 230-400$ mesh; $\mathrm{CH}_{2} \mathrm{Cl}_{2} / \mathrm{MeOH}$ 15:1-0:1, $950 \mathrm{~mL}$ fractions) to form ten subfractions: A5-1-A5-10. Fraction A5-3 (625 mg) was purified by CC (28 $\mathrm{g}$ of $\mathrm{SiO}_{2}, 230-400$ mesh, $\mathrm{CHCl}_{3} /$ acetone (7:1-0:1), $250 \mathrm{~mL}$ fractions) to give nine subfractions: A5-3-1-A5-3-9. Fraction A5-3-5 (88 $\mathrm{mg}$ ) was further purified by preparative TLC $\left(\mathrm{SiO}_{2} ; \mathrm{CH}_{2} \mathrm{Cl}_{2}\right.$ /acetone 8:1) to yield a mixture of $6 \beta$-hydroxystigmast-4-en-3-one (14) and 6 $\beta$-hydroxystigmasta-4,22-dien-3-one (15) (3.7 mg). Fraction A7 (7.3 g) was subjected to CC (330 g of $\mathrm{SiO}_{2}, 230-400$ mesh; $\mathrm{CHCl}_{3} / \mathrm{MeOH}$ 10:1-0:1, $800 \mathrm{~mL}$ fractions) to give nine subfractions: A7-1-A7-9. A part (142 mg) of fraction A7-2 was further purified by preparative TLC $\left(\mathrm{SiO}_{2} ; \mathrm{CH}_{2} \mathrm{Cl}_{2} / \mathrm{MeOH}\right.$ 15:1) to form (-)-deoxypodophyllotoxin (8) (7.2 mg). A part (133 mg) of fraction A7-3 was further purified by preparative TLC $\left(\mathrm{SiO}_{2} ; \mathrm{CHCl}_{3} / \mathrm{MeOH} 12: 1\right)$ to yield (-)-yatein (10) (5.1 mg). A part (136 mg) of fraction A7-4 was further purified by preparative TLC $\left(\mathrm{SiO}_{2} ; \mathrm{CHCl}_{3} / \mathrm{MeOH}\right.$ 9:1) to obtain 2-O-methyl-7-oxolaetine (3) $(5.3 \mathrm{mg})$. A part $(118 \mathrm{mg})$ of fraction A7-6 was further purified by preparative TLC $\left(\mathrm{SiO}_{2} ; \mathrm{CH}_{2} \mathrm{Cl}_{2} / \mathrm{MeOH}\right.$ 5:1) to produce 7-oxonorisocorydine (7) (6.5 mg). Fraction A7-7 (650 mg) was purified by MPLC (silica column, $\mathrm{CH}_{2} \mathrm{Cl}_{2} / \mathrm{MeOH}$ 9:1-0:1) to form seven subfractions (each $170 \mathrm{ml}, \mathrm{A} 7-7-1-\mathrm{A7}-7-7)$. A part (112 mg) of fraction A7-7-4 was further purified by preparative TLC $\left(\mathrm{SiO}_{2} ; \mathrm{CHCl}_{3}\right.$ /acetone 5:1) to form 4'-O-demethyl-7-O-methyldehydropodophyllotoxin (2) (5.5 $\mathrm{mg})$. A part (125 mg) of fraction A7-7-5 was purified by preparative TLC $\left(\mathrm{SiO}_{2} ; \mathrm{CH}_{2} \mathrm{Cl}_{2} /\right.$ acetone $\left.4: 1\right)$ to obtain dehydropodophyllotoxin (9) $(6.9 \mathrm{mg})$. A part (122 mg) of fraction A7-8 was purified by preparative TLC $\left(\mathrm{SiO}_{2} ; \mathrm{CH}_{2} \mathrm{Cl}_{2} /\right.$ EtOAc 2:1) to yield $\mathrm{N}$-trans-feruloylmethoxytyramine (11) (4.9 mg). Fraction A8 (7.2 g) was subjected to CC (325 g of $\mathrm{SiO}_{2}, 230-400$ mesh; $\mathrm{CH}_{2} \mathrm{Cl}_{2} / \mathrm{MeOH} 8: 1-0: 1,850 \mathrm{~mL}$ fractions) to give ten subfractions: A8-1-A8-10. Fraction A8-2 (530 mg) was purified by MPLC (silica column, $\mathrm{CHCl}_{3} / \mathrm{MeOH}$ 7:1-0:1) to form six subfractions (each $180 \mathrm{ml}$, A8-2-1-A8-2-6). Fraction A8-2-4 (83 mg) was further purified by preparative TLC $\left(\mathrm{SiO}_{2} ; \mathrm{CH}_{2} \mathrm{Cl}_{2}\right.$ /acetone 6:1) to obtain hernandonine (4) $(8.2 \mathrm{mg})$. Fraction A8-5 (135 mg) was further purified by preparative TLC $\left(\mathrm{SiO}_{2} ; \mathrm{CH}_{2} \mathrm{Cl}_{2} / \mathrm{MeOH}\right.$ 4:1) to obtain oxohernagine $(6)(7.1 \mathrm{mg})$. Fraction A8-6 (135 mg) was further purified by preparative TLC $\left(\mathrm{SiO}_{2} ; \mathrm{CHCl}_{3} / \mathrm{MeOH} 3: 1\right)$ to yield oxohernangerine (5) (6.5 mg). Fraction A9 (6.4 g) was subjected to $\mathrm{CC}\left(290 \mathrm{~g}\right.$ of $\mathrm{SiO}_{2}, 230-400$ mesh; $\mathrm{CHCl}_{3} / \mathrm{MeOH}$ 6:1-0:1, $1 \mathrm{~L}$ fractions) to obtain eight subfractions: A9-1-A9-8. A part (142 mg) of fraction A9-3 was purified by preparative TLC $\left(\mathrm{SiO}_{2} ; \mathrm{CHCl}_{3} / \mathrm{MeOH}^{-}\right.$ 5:1) to obtain 3-hydroxyhernandonine (1) (4.5 mg). A part (105 mg) of fraction A9-5 was purified by preparative TLC $\left(\mathrm{SiO}_{2} ; \mathrm{CH}_{2} \mathrm{Cl}_{2} / \mathrm{MeOH} 4: 1\right)$ to obtain oxohernangerine (5) (5.9 mg).

3-Hydroxyhernandonine (1): yellow needles; m.p. $268-270{ }^{\circ} \mathrm{C}(\mathrm{MeOH}) ; \mathrm{UV}(\mathrm{MeOH}): \lambda_{\max }(\log \varepsilon)=220$ (3.90), 268 (3.79), 284 (3.78), 343 (3.46), 362 (3.47) nm; IR (KBr): $v_{\max }=3315$ (OH), 1652 (C=O), 1060, 969 $\left(\mathrm{OCH}_{2} \mathrm{O}\right) \mathrm{cm}^{-1},{ }^{1} \mathrm{H}-\mathrm{NMR}\left(\mathrm{CDCl}_{3}, 500 \mathrm{MHz}\right): \delta 6.20\left(2 \mathrm{H}, \mathrm{s}, \mathrm{OCH}_{2} \mathrm{O}-10,11\right), 6.28\left(2 \mathrm{H}, \mathrm{s}, \mathrm{OCH}{ }_{2} \mathrm{O}-1,2\right)$, 
$6.52\left(1 \mathrm{H}, \mathrm{s}, \mathrm{D}_{2} \mathrm{O}\right.$ exchangeable, OH-3), $7.08(1 \mathrm{H}, \mathrm{d}, J=8.5 \mathrm{~Hz}, \mathrm{H}-9), 8.10(1 \mathrm{H}, \mathrm{d}, J=5.0 \mathrm{~Hz}, \mathrm{H}-4), 8.28$ $(1 \mathrm{H}, \mathrm{d}, J=8.5 \mathrm{~Hz}, \mathrm{H}-8), 8.88(1 \mathrm{H}, \mathrm{d}, J=5.0 \mathrm{~Hz}, \mathrm{H}-5) ;{ }^{13} \mathrm{C}-\mathrm{NMR}\left(\mathrm{CDCl}_{3}, 125 \mathrm{MHz}\right): \delta 101.3\left(\mathrm{OCH}_{2} \mathrm{O}-1,2\right)$, $101.7\left(\mathrm{OCH}_{2} \mathrm{O}-10,11\right), 108.6$ (C-9), 114.9 (C-11b), 118.7 (C-8), 119.1 (C-4), 122.3 (C-11a), 122.9 (C-11c), 123.9 (C-3a), 127.6 (C-7a), 139.2 (C-2), 145.2 (C-5), 145.8 (C-11), 148.4 (C-3), 149.6 (C-1), 150.4 (C-10), 157.3 (C-6a), 182.5 (C-7); ESI-MS: $m / z=358[\mathrm{M}+\mathrm{Na}]^{+}$; HR-ESI-MS: $m / z=358.0325[\mathrm{M}+\mathrm{Na}]^{+}$(calcd $^{2}$ for $\left.\mathrm{C}_{18} \mathrm{H}_{9} \mathrm{NO}_{6} \mathrm{Na}, 358.0328\right)$.

4'-O-Demethyl-7-O-methyldehydropodophyllotoxin (2): colorless needles; m.p. 273-275 ${ }^{\circ} \mathrm{C}(\mathrm{MeOH})$; UV $(\mathrm{MeOH}): \lambda_{\max }(\log \varepsilon)=223(4.47), 262(4.58), 321(3.98), 355(3.69) \mathrm{nm}$; IR $(\mathrm{KBr}): v_{\max }=3452(\mathrm{OH}), 1764$ $(\mathrm{C}=\mathrm{O}) \mathrm{cm}^{-1} ;{ }^{1} \mathrm{H}-\mathrm{NMR}\left(\mathrm{CDCl}_{3}, 500 \mathrm{MHz}\right): \delta 3.88\left(6 \mathrm{H}, \mathrm{s}, \mathrm{OMe}-3^{\prime}\right.$ and $\left.\mathrm{OMe}-5^{\prime}\right), 4.09$ (3H, s, OMe-7), 5.52 $(2 \mathrm{H}, \mathrm{s}, \mathrm{H}-9), 5.65\left(1 \mathrm{H}, \mathrm{br} \mathrm{s}, \mathrm{D}_{2} \mathrm{O}\right.$ exchangeable, $\left.\mathrm{OH}-4^{\prime}\right), 6.09\left(2 \mathrm{H}, \mathrm{s}, \mathrm{OCH}_{2} \mathrm{O}\right), 6.57\left(2 \mathrm{H}, \mathrm{s}, \mathrm{H}-2^{\prime}\right.$, and H-6 $), 7.07$ (1H, s, H-5), 7.57 (1H, s, H-2); ${ }^{13} \mathrm{C}-\mathrm{NMR}\left(\mathrm{CDCl}_{3}, 125 \mathrm{MHz}\right): \delta 56.0\left(\mathrm{OMe}-3^{\prime}\right), 56.0\left(\mathrm{OMe}-5^{\prime}\right)$, 59.9 (OMe-7), 66.4 (C-9), $98.4(\mathrm{C}-2), 101.8\left(\mathrm{OCH}_{2} \mathrm{O}\right), 103.9(\mathrm{C}-5), 107.7\left(\mathrm{C}-2^{\prime}\right), 107.7\left(\mathrm{C}-6^{\prime}\right), 119.5\left(\mathrm{C}-8^{\prime}\right)$, 125.8 (C-8), 127.8 (C-6), $130.4(\mathrm{C}-1), 132.2\left(\mathrm{C}-1^{\prime}\right), 133.6\left(\mathrm{C}-4^{\prime}\right), 137.7\left(\mathrm{C}-7^{\prime}\right), 148.5$ (C-7), 148.9 (C-4), 148.9 $\left(\mathrm{C}-3^{\prime}\right), 148.9\left(\mathrm{C}-5^{\prime}\right), 150.0(\mathrm{C}-3), 169.3\left(\mathrm{C}-9^{\prime}\right)$; ESI-MS: $m / z=433$ [M + Na] ${ }^{+}$; HR-ESI-MS: $m / z=433.0898$ $[\mathrm{M}+\mathrm{Na}]^{+}$(calcd for $\mathrm{C}_{22} \mathrm{H}_{18} \mathrm{O}_{8} \mathrm{Na}$, 433.0899).

2-O-Methyl-7-oxolaetine (3): yellow needles; m.p. > $300{ }^{\circ} \mathrm{C}(\mathrm{MeOH}) ; \mathrm{UV}(\mathrm{MeOH}): \lambda_{\max }(\log \varepsilon)=221$ (4.49), 266 (4.33), 362 (4.00), 427 (3.95) nm; IR (KBr): $v_{\max }=1652(\mathrm{C}=\mathrm{O}) \mathrm{cm}^{-1} ;{ }^{1} \mathrm{H}-\mathrm{NMR}\left(\mathrm{CDCl}_{3}\right.$, $400 \mathrm{MHz}): \delta 3.93(3 \mathrm{H}, \mathrm{s}, \mathrm{OMe}-1), 6.21\left(2 \mathrm{H}, \mathrm{s}, \mathrm{OCH}_{2} \mathrm{O}-10,11\right), 7.08(1 \mathrm{H}, \mathrm{d}, J=8.4 \mathrm{~Hz}, \mathrm{H}-9), 7.21(1 \mathrm{H}, \mathrm{s}$, H-3), $7.77(1 \mathrm{H}, \mathrm{d}, J=5.2 \mathrm{~Hz}, \mathrm{H}-4), 8.24(1 \mathrm{H}, \mathrm{d}, J=8.4 \mathrm{~Hz}, \mathrm{H}-8), 8.86(1 \mathrm{H}, \mathrm{d}, J=5.2 \mathrm{~Hz}, \mathrm{H}-5)$; ESI-MS: $m / z=358[\mathrm{M}+\mathrm{Na}]^{+} ;$HR-ESI-MS: $m / z=358.0692[\mathrm{M}+\mathrm{Na}]^{+}$(calcd for $\left.\mathrm{C}_{19} \mathrm{H}_{13} \mathrm{O}_{5} \mathrm{Na}, 358.0691\right)$.

Hernandonine (4): yellow needles; m.p. > $350^{\circ} \mathrm{C}\left(\mathrm{CH}_{2} \mathrm{Cl}_{2}-\mathrm{MeOH}\right) ; \mathrm{UV}(\mathrm{MeOH}): \lambda_{\max }(\log \varepsilon)=222(4.50)$, 265 (4.34), 295 (sh, 3.90), 312 (sh, 3.63), 364 (4.02), 428 (3.97) nm; IR (KBr): $v_{\max }=1651$ (C=O), 1062, 971 $\left(\mathrm{OCH}_{2} \mathrm{O}\right) \mathrm{cm}^{-1} ;{ }^{1} \mathrm{H}-\mathrm{NMR}\left(\mathrm{CDCl}_{3}, 500 \mathrm{MHz}\right): \delta 6.20\left(2 \mathrm{H}, \mathrm{s}, \mathrm{OCH}_{2} \mathrm{O}-10,11\right), 6.28\left(2 \mathrm{H}, \mathrm{s}, \mathrm{OCH}_{2} \mathrm{O}-1,2\right)$, $7.08(1 \mathrm{H}, \mathrm{d}, J=8.5 \mathrm{~Hz}, \mathrm{H}-9), 7.21(1 \mathrm{H}, \mathrm{s}, \mathrm{H}-3), 7.74(1 \mathrm{H}, \mathrm{d}, J=5.0 \mathrm{~Hz}, \mathrm{H}-4), 8.29(1 \mathrm{H}, \mathrm{d}, J=8.5 \mathrm{~Hz}, \mathrm{H}-8)$, $8.85(1 \mathrm{H}, \mathrm{d}, J=5.0 \mathrm{~Hz}, \mathrm{H}-5)$; ESI-MS: $m / z=342[\mathrm{M}+\mathrm{Na}]^{+}$.

Oxohernangerine (5): yellow prisms; m.p. $257-258{ }^{\circ} \mathrm{C}(\mathrm{MeOH}) ; \mathrm{UV}(\mathrm{MeOH}): \lambda_{\max }(\log \varepsilon)=211$ (4.55), 252 (4.46), 268 (sh, 4.42), 316 (3.87), 362 (4.04), 408 (4.02), 477 (3.55) nm; IR (KBr): $v_{\max }=3415(\mathrm{OH})$, $1642(\mathrm{C}=\mathrm{O}) \mathrm{cm}^{-1},{ }^{1} \mathrm{H}-\mathrm{NMR}\left(\mathrm{CDCl}_{3}, 400 \mathrm{MHz}\right): \delta 3.68(3 \mathrm{H}, \mathrm{s}, \mathrm{OMe}-11), 6.32\left(2 \mathrm{H}, \mathrm{s}, \mathrm{OCH}_{2} \mathrm{O}-1,2\right), 7.24$ $(1 \mathrm{H}, \mathrm{d}, J=8.4 \mathrm{~Hz}, \mathrm{H}-9), 7.27(1 \mathrm{H}, \mathrm{s}, \mathrm{H}-3), 7.76(1 \mathrm{H}, \mathrm{d}, J=5.2 \mathrm{~Hz}, \mathrm{H}-4), 8.37(1 \mathrm{H}, \mathrm{d}, J=8.4 \mathrm{~Hz}, \mathrm{H}-8), 8.86$ $(1 \mathrm{H}, \mathrm{d}, J=5.2 \mathrm{~Hz}, \mathrm{H}-5)$; ESI-MS: $m / z=344[\mathrm{M}+\mathrm{Na}]^{+}$.

Oxohernagine (6): yellow prisms; m.p. $253-255^{\circ} \mathrm{C}(\mathrm{MeOH}) ; \mathrm{UV}(\mathrm{MeOH}): \lambda_{\max }(\log \varepsilon)=213$ (4.51), 274 (4.41), 361 (3.95), 403 (3.92) nm; IR (KBr): $v_{\max }=3424(\mathrm{OH}), 1650(\mathrm{C}=\mathrm{O}) \mathrm{cm}^{-1} ;{ }^{1} \mathrm{H}-\mathrm{NMR}\left(\mathrm{CDCl}_{3}\right.$, $400 \mathrm{MHz}): \delta 3.54$ (3H, s, OMe-1), 3.76 (3H, s, OMe-11), $4.11(3 \mathrm{H}, \mathrm{s}, \mathrm{OMe}-2), 7.21(1 \mathrm{H}, \mathrm{s}, \mathrm{H}-3), 7.22(1 \mathrm{H}$, $\mathrm{d}, J=8.4 \mathrm{~Hz}, \mathrm{H}-9), 7.77(1 \mathrm{H}, \mathrm{d}, J=5.2 \mathrm{~Hz}, \mathrm{H}-4), 8.31(1 \mathrm{H}, \mathrm{d}, J=8.4 \mathrm{~Hz}, \mathrm{H}-8), 8.86(1 \mathrm{H}, \mathrm{d}, J=5.2 \mathrm{~Hz}$, H-5); ESI-MS: $m / z=360[\mathrm{M}+\mathrm{Na}]^{+}$.

7-Oxonorisocorydine (7): yellow needles; m.p. $250-252{ }^{\circ} \mathrm{C}\left(\right.$ EtOAc); $\mathrm{UV}(\mathrm{MeOH}): \lambda_{\max }(\log \varepsilon)=212$ (4.49), 273 (4.40), 362 (3.94), 403 (3.90) nm; IR (KBr): $v_{\max }=3385(\mathrm{OH}), 1653(\mathrm{C}=\mathrm{O}) \mathrm{cm}^{-1} ;{ }^{1} \mathrm{H}-\mathrm{NMR}$ $\left(\mathrm{CDCl}_{3}, 400 \mathrm{MHz}\right): \delta 3.53(3 \mathrm{H}, \mathrm{s}, \mathrm{OMe}-1), 4.03(3 \mathrm{H}, \mathrm{s}, \mathrm{OMe}-10), 4.08(3 \mathrm{H}, \mathrm{s}, \mathrm{OMe}-2), 7.14(1 \mathrm{H}, \mathrm{d}, J=8.4$ $\mathrm{Hz}, \mathrm{H}-9), 7.23(1 \mathrm{H}, \mathrm{s}, \mathrm{H}-3), 7.77(1 \mathrm{H}, \mathrm{d}, J=5.2 \mathrm{~Hz}, \mathrm{H}-4), 8.28(1 \mathrm{H}, \mathrm{d}, J=8.4 \mathrm{~Hz}, \mathrm{H}-8), 8.86(1 \mathrm{H}, \mathrm{d}, J=5.2$ $\mathrm{Hz}, \mathrm{H}-5)$; ESI-MS: $m / z=360[\mathrm{M}+\mathrm{Na}]^{+}$.

(-)-Deoxypodophyllotoxin (8): colorless needles; m.p. $168-170{ }^{\circ} \mathrm{C}(\mathrm{MeOH}) ; \mathrm{UV}(\mathrm{MeOH}): \lambda_{\max }(\log \varepsilon)=$ 212 (4.62), 291 (3.68) nm; IR (KBr): $v_{\max }=1765(\mathrm{C}=\mathrm{O}), 1581,1502,1474$ (aromatic ring $\mathrm{C}=\mathrm{C}$ stretch), 1032, $941\left(\mathrm{OCH}_{2} \mathrm{O}\right) \mathrm{cm}^{-1} ;{ }^{1} \mathrm{H}-\mathrm{NMR}\left(\mathrm{CDCl}_{3}, 500 \mathrm{MHz}\right): \delta 2.73(3 \mathrm{H}, \mathrm{m}, \mathrm{H}-7, \mathrm{H}-8$, and H-8 $), 3.07(1 \mathrm{H}, \mathrm{m}$, H-7), 3.75 (6H, s, OMe- $3^{\prime}$, and OMe-5'), 3.80 (3H, s, OMe-4'), $3.92(1 \mathrm{H}, \mathrm{m}, \mathrm{H}-9), 4.46(1 \mathrm{H}, \mathrm{m}, \mathrm{H}-9), 4.60$ $\left(1 \mathrm{H}, \mathrm{d}, J=3.5 \mathrm{~Hz}, \mathrm{H}-7^{\prime}\right), 5.93,5.95$ (each $1 \mathrm{H}$, each $\left.\mathrm{d}, J=1.5 \mathrm{~Hz}, \mathrm{OCH}_{2} \mathrm{O}\right), 6.34\left(2 \mathrm{H}, \mathrm{s}, \mathrm{H}-2^{\prime}\right.$, and $\left.\mathrm{H}-6^{\prime}\right)$, $6.52(1 \mathrm{H}, \mathrm{s}, \mathrm{H}-5), 6.67(1 \mathrm{H}, \mathrm{s}, \mathrm{H}-2)$; ESI-MS: $m / z=421[\mathrm{M}+\mathrm{Na}]^{+}$. 
Dehydropodophyllotoxin (9): colorless needles; m.p. $264-266{ }^{\circ} \mathrm{C}\left(\mathrm{CH}_{2} \mathrm{Cl}_{2}-\mathrm{MeOH}\right) ; \mathrm{UV}(\mathrm{MeOH}): \lambda_{\max }$ $(\log \varepsilon)=262(4.57), 311(3.95), 321(3.97) \mathrm{nm} ; \mathrm{IR}(\mathrm{KBr}): v_{\max }=3421(\mathrm{OH}), 1762(\mathrm{C}=\mathrm{O}) \mathrm{cm}^{-1} ;{ }^{1} \mathrm{H}-\mathrm{NMR}$ $\left(\mathrm{CDCl}_{3}, 500 \mathrm{MHz}\right): \delta 3.83\left(6 \mathrm{H}, \mathrm{s}, \mathrm{OMe}-3^{\prime}\right.$, and OMe-5'), 3.95 (3H, s, OMe-4'), 5.37 (2H, br s, H-9), 5.68 $\left(1 \mathrm{H}, \mathrm{br} \mathrm{s}, \mathrm{D}_{2} \mathrm{O}\right.$ exchangeable, $\left.\mathrm{OH}-7\right), 6.10\left(2 \mathrm{H}, \mathrm{s}, \mathrm{OCH}_{2} \mathrm{O}\right), 6.52\left(2 \mathrm{H}, \mathrm{s}, \mathrm{H}-2^{\prime}\right.$, and $\left.\mathrm{H}-6^{\prime}\right), 7.09(1 \mathrm{H}, \mathrm{s}, \mathrm{H}-5)$, $7.49(1 \mathrm{H}, \mathrm{s}, \mathrm{H}-2)$; ESI-MS: $m / z=433[\mathrm{M}+\mathrm{Na}]^{+}$.

(-)-Yatein (10): yellowish solid (MeOH); UV (MeOH): $\lambda_{\max }(\log \varepsilon)=212$ (4.35), 230 (sh, 3.93), 287 (3.47) $\mathrm{nm}$; IR (KBr): $v_{\max }=1764(\mathrm{C}=\mathrm{O}), 1591,1502,1488$ (aromatic ring $\mathrm{C}=\mathrm{C}$ stretch), 1037, $925\left(\mathrm{OCH}_{2} \mathrm{O}\right)$ $\mathrm{cm}^{-1} ;{ }^{1} \mathrm{H}-\mathrm{NMR}\left(\mathrm{CDCl}_{3}, 400 \mathrm{MHz}\right): \delta 2.49(1 \mathrm{H}, \mathrm{m}, \mathrm{H}-8), 2.53(1 \mathrm{H}, \mathrm{m}, \mathrm{H}-7 \alpha), 2.58\left(1 \mathrm{H}, \mathrm{m}, \mathrm{H}-8^{\prime}\right), 2.62$ $(1 \mathrm{H}, \mathrm{dd}, J=13.2,6.4 \mathrm{~Hz}, \mathrm{H}-7 \beta), 2.89\left(1 \mathrm{H}, \mathrm{dd}, J=14.0,6.2 \mathrm{~Hz}, \mathrm{H}^{\prime}{ }^{\prime} \alpha\right), 2.93(1 \mathrm{H}, \mathrm{dd}, J=14.0,5.2 \mathrm{~Hz}$, $\left.\mathrm{H}-7^{\prime} \beta\right), 3.82\left(6 \mathrm{H}, \mathrm{s}, \mathrm{OMe}-3^{\prime}\right.$, and OMe-5'), $3.83\left(3 \mathrm{H}, \mathrm{s}, \mathrm{OMe}-4^{\prime}\right), 3.88(1 \mathrm{H}, \mathrm{dd}, J=9.2,7.6 \mathrm{~Hz}, \mathrm{H}-9 \beta)$, $4.18(1 \mathrm{H}, \mathrm{dd}, J=9.2,7.2 \mathrm{~Hz}, \mathrm{H}-9 \alpha), 5.93,5.94\left(\right.$ each $1 \mathrm{H}$, each d, $\left.J=1.2 \mathrm{~Hz}, \mathrm{OCH}_{2} \mathrm{O}\right), 6.36\left(2 \mathrm{H}, \mathrm{s}, \mathrm{H}-2^{\prime}\right.$, and $\left.\mathrm{H}-6^{\prime}\right), 6.46(1 \mathrm{H}, \mathrm{d}, J=1.6 \mathrm{~Hz}, \mathrm{H}-2), 6.47(1 \mathrm{H}, \mathrm{dd}, J=7.6,1.6 \mathrm{~Hz}, \mathrm{H}-6), 6.69(1 \mathrm{H}, \mathrm{d}, J=7.6 \mathrm{~Hz}, \mathrm{H}-5)$; ESI-MS: $m / z=423[\mathrm{M}+\mathrm{Na}]^{+}$.

$N$-trans-Feruloylmethoxytyramine (11): white needles; m.p. $112-114{ }^{\circ} \mathrm{C}\left(\mathrm{CHCl}_{3}-\mathrm{MeOH}\right)$; UV (MeOH): $\lambda_{\max }(\log \varepsilon)=221(3.61), 290(2.86), 319(3.34) \mathrm{nm}$; IR (KBr): $v_{\max }=3362(\mathrm{OH}), 1652(\mathrm{C}=\mathrm{O}) \mathrm{cm}^{-1}$; ${ }^{1} \mathrm{H}-\mathrm{NMR}\left(\mathrm{CDCl}_{3}, 400 \mathrm{MHz}\right): \delta 2.82(2 \mathrm{H}, \mathrm{t}, J=6.8 \mathrm{~Hz}, \mathrm{H}-11), 3.62(2 \mathrm{H}, \mathrm{q}, J=6.8 \mathrm{~Hz}, \mathrm{H}-10), 3.88(3 \mathrm{H}$, $\mathrm{s}$, OMe-14), $3.92(3 \mathrm{H}, \mathrm{s}, \mathrm{OMe}-3), 5.52\left(1 \mathrm{H}, \mathrm{br} \mathrm{t}, J=6.8 \mathrm{~Hz}, \mathrm{D}_{2} \mathrm{O}\right.$ exchangeable, $\left.\mathrm{NH}\right), 5.53\left(1 \mathrm{H}, \mathrm{s}, \mathrm{D}_{2} \mathrm{O}\right.$ exchangeable, $\mathrm{OH}), 5.79\left(1 \mathrm{H}, \mathrm{s}, \mathrm{D}_{2} \mathrm{O}\right.$ exchangeable, $\left.\mathrm{OH}\right), 6.16(1 \mathrm{H}, \mathrm{d}, J=15.6 \mathrm{~Hz}, \mathrm{H}-8), 6.71(1 \mathrm{H}, \mathrm{dd}$, $J=8.0,1.6 \mathrm{~Hz}, \mathrm{H}-17), 6.73(1 \mathrm{H}, \mathrm{d}, J=1.6 \mathrm{~Hz}, \mathrm{H}-13), 6.87(1 \mathrm{H}, \mathrm{d}, J=8 . \mathrm{Hz}, \mathrm{H}-16), 6.90(1 \mathrm{H}, \mathrm{d}, J=8.4 \mathrm{~Hz}$, H-5), $6.97(1 \mathrm{H}, \mathrm{d}, J=1.6 \mathrm{~Hz}, \mathrm{H}-2), 7.04(1 \mathrm{H}, \mathrm{dd}, J=8.4,1.6 \mathrm{~Hz}, \mathrm{H}-5), 7.53(1 \mathrm{H}, \mathrm{d}, J=15.6 \mathrm{~Hz}, \mathrm{H}-7)$; ESI-MS: $m / z=366[\mathrm{M}+\mathrm{Na}]^{+}$.

Mixture of $\beta$-Sitostenone (12) and stigmasta-4,22-dien-3-one (13): colorless needles; m.p. $88-90{ }^{\circ} \mathrm{C}$ $(\mathrm{MeOH}) ;[\alpha]_{\mathrm{D}}^{25}=+85.8^{\circ}\left(c 0.18, \mathrm{CHCl}_{3}\right) ; \mathrm{UV}(\mathrm{MeOH}): \lambda_{\max }(\log \varepsilon)=242(4.21) ; \mathrm{IR}(\mathrm{KBr}): v_{\max }=1685$ $(\mathrm{C}=\mathrm{O}) \mathrm{cm}^{-1} ;{ }^{1} \mathrm{H}-\mathrm{NMR}\left(\mathrm{CDCl}_{3}, 400 \mathrm{MHz}\right)$ of 12: $\delta 0.70(3 \mathrm{H}, \mathrm{s}, \mathrm{H}-18), 0.81(3 \mathrm{H}, \mathrm{d}, J=6.8 \mathrm{~Hz}, \mathrm{H}-27), 0.83$ $(3 \mathrm{H}, \mathrm{d}, J=6.8 \mathrm{~Hz}, \mathrm{H}-26), 0.86(3 \mathrm{H}, \mathrm{t}, J=7.2 \mathrm{~Hz}, \mathrm{H}-29), 0.92(3 \mathrm{H}, \mathrm{d}, J=6.4 \mathrm{~Hz}, \mathrm{H}-21), 1.18(3 \mathrm{H}, \mathrm{s}, \mathrm{H}-19)$, $5.71(1 \mathrm{H}, \mathrm{s}, \mathrm{H}-4) ;{ }^{1} \mathrm{H}-\mathrm{NMR}\left(\mathrm{CDCl}_{3}, 400 \mathrm{MHz}\right)$ of 13: $\delta 0.72(3 \mathrm{H}, \mathrm{s}, \mathrm{H}-18), 0.79(3 \mathrm{H}, \mathrm{d}, J=6.8 \mathrm{~Hz}, \mathrm{H}-27)$, $0.82(3 \mathrm{H}, \mathrm{t}, J=7.2 \mathrm{~Hz}, \mathrm{H}-29), 0.83(3 \mathrm{H}, \mathrm{d}, J=6.8 \mathrm{~Hz}, \mathrm{H}-26), 1.02(3 \mathrm{H}, \mathrm{d}, J=6.8 \mathrm{~Hz}, \mathrm{H}-21), 1.18(3 \mathrm{H}$, s, H-19), $5.02(1 \mathrm{H}, \mathrm{dd}, J=15.2,8.8 \mathrm{~Hz}, \mathrm{H}-23), 5.14(1 \mathrm{H}, \mathrm{dd}, J=15.2,8.8 \mathrm{~Hz}, \mathrm{H}-22), 5.71(1 \mathrm{H}, \mathrm{s}, \mathrm{H}-4)$; ESI-MS of 12: $m / z=435[\mathrm{M}+\mathrm{Na}]^{+}$; ESI-MS of 13: $m / z=433[\mathrm{M}+\mathrm{Na}]^{+}$.

Mixture of 6 $\beta$-Hydroxystigmast-4-en-3-one (14) and 6 $\beta$-hydroxystigmasta-4,22-dien-3-one (15): colorless needles; m.p. $208-209^{\circ} \mathrm{C}\left(\mathrm{CH}_{2} \mathrm{Cl}_{2}-\mathrm{MeOH}\right) ;[\alpha]_{\mathrm{D}}^{25}=+29.7^{\circ}\left(c 0.17, \mathrm{CHCl}_{3}\right) ; \mathrm{UV}(\mathrm{MeOH}): \lambda_{\max }(\log \varepsilon)=$ 235 (4.11) nm; IR (KBr): $v_{\max }=3412(\mathrm{OH}), 1679(\mathrm{C}=\mathrm{O}) \mathrm{cm}^{-1} ;{ }^{1} \mathrm{H}-\mathrm{NMR}\left(\mathrm{CDCl}_{3}, 400 \mathrm{MHz}\right)$ of 14: $\delta 0.74$ $(3 \mathrm{H}, \mathrm{s}, \mathrm{H}-18), 0.81(3 \mathrm{H}, \mathrm{d}, J=6.8 \mathrm{~Hz}, \mathrm{H}-27), 0.84(3 \mathrm{H}, \mathrm{d}, J=7.2 \mathrm{~Hz}, \mathrm{H}-26), 0.87(3 \mathrm{H}, \mathrm{t}, J=7.2 \mathrm{~Hz}, \mathrm{H}-29)$, $0.92(3 \mathrm{H}, \mathrm{d}, J=6.4 \mathrm{~Hz}, \mathrm{H}-21), 1.38(3 \mathrm{H}, \mathrm{s}, \mathrm{H}-19), 4.35(1 \mathrm{H}, \mathrm{br} \mathrm{s}, \mathrm{H}-6), 5.82(1 \mathrm{H}, \mathrm{s}, \mathrm{H}-4) ;{ }^{1} \mathrm{H}-\mathrm{NMR}\left(\mathrm{CDCl}_{3}\right.$, $500 \mathrm{MHz})$ of 15: $\delta 0.76(3 \mathrm{H}, \mathrm{s}, \mathrm{H}-18), 0.80(3 \mathrm{H}, \mathrm{d}, J=6.8 \mathrm{~Hz}, \mathrm{H}-27), 0.81(3 \mathrm{H}, \mathrm{d}, J=6.8 \mathrm{~Hz}, \mathrm{H}-26), 0.85$ $(3 \mathrm{H}, \mathrm{t}, J=7.2 \mathrm{~Hz}, \mathrm{H}-29), 1.02(3 \mathrm{H}, \mathrm{d}, J=6.8 \mathrm{~Hz}, \mathrm{H}-21), 1.38$ (3H, s, H-19), 4.35 (1H, br s, H-6), 5.03 $(1 \mathrm{H}, \mathrm{dd}, J=15.2,8.6 \mathrm{~Hz}, \mathrm{H}-23), 5.15(1 \mathrm{H}, \mathrm{dd}, J=15.2,8.6 \mathrm{~Hz}, \mathrm{H}-22), 5.82(1 \mathrm{H}, \mathrm{s}, \mathrm{H}-4)$; ESI-MS of 14: $m / z=451[\mathrm{M}+\mathrm{Na}]^{+} ;$ESI-MS of 15: $m / z=449[\mathrm{M}+\mathrm{Na}]^{+}$.

\subsection{Biological Assay}

The effect of the isolates on the neutrophil proinflammatory response was assessed by detecting the inhibition of elastase release and $\mathrm{O}_{2}{ }^{--}$generation in fMLP/CB-activated neutrophils in a concentration-dependent manner.

\subsubsection{Mensuration of Human Neutrophils}

Human neutrophils from the venous blood of adult, healthy volunteers (20-27 years old) were isolated by a standard pattern of dextran sedimentation before centrifugation in a Ficoll Hypaque gradient and hypotonic lysis of the erythrocytes [27]. The purified neutrophils had $>98 \%$ viable cells, 
as detected by the trypan blue exclusion method [28], were resuspended in a calcium $\left(\mathrm{Ca}^{2+}\right)$-free HBSS buffer at $\mathrm{pH} 7.4$ and were kept at $4{ }^{\circ} \mathrm{C}$ prior to use.

\subsubsection{Mensuration of Superoxide Anion $\left(\mathrm{O}_{2}{ }^{\bullet-}\right)$ Generation}

The assay for the measurement of $\mathrm{O}_{2}{ }^{\bullet-}$ generation was based on the superoxide dismutase (SOD)-inhibitable reduction of ferricytochrome $c[29,30]$. In short, after supplementation with $1 \mathrm{mM}$ $\mathrm{Ca}^{2+}$ and $0.5 \mathrm{mg} / \mathrm{mL}$ ferricytochrome $c$, neutrophils $\left(6 \times 10^{5} / \mathrm{mL}\right)$ were equilibrated at $37^{\circ} \mathrm{C}$ for $2 \mathrm{~min}$ and incubated with varied concentrations $(10-0.01 \mu \mathrm{g} / \mathrm{mL}$ ) of either DMSO (as a control) or tested compounds 1-15 (purity $\geq 98 \%$ ) for $5 \mathrm{~min}$. Cells were incubated with cytochalasin B $(1 \mu \mathrm{g} / \mathrm{mL})$ for 3 min before they were activated with $100 \mathrm{nM}$ formyl-L-methionyl-L-leucyl-L-phenylalanine for $10 \mathrm{~min}$. Changes in absorbance with the reduction of ferricytochrome $c$ at $550 \mathrm{~nm}$ were constantly detected in a double-beam, six-cell positioner spectrophotometer with continuous stirring (Hitachi U-3010, Tokyo, Japan). Calculations were founded on differences in the reactions with and without SOD $(100 \mathrm{U} / \mathrm{mL})$ divided by the extinction coefficient for the reduction of ferricytochrome $c(\varepsilon=21.1 / \mathrm{mM} / 10 \mathrm{~mm})$.

\subsubsection{Mensuration of Elastase Release}

The degranulation of azurophilic granules was measured by determining elastase release as reported previously [30,31]. Assays were carried out by applying MeO-Suc-Ala-Ala-Pro-Val$p$-nitroanilide as the elastase substrate. In brief, after supplementation with MeO-Suc-Ala-Ala-Pro-Val$p$-nitroanilide $(100 \mu \mathrm{M})$, neutrophils $\left(6 \times 10^{5} / \mathrm{mL}\right)$ were equilibrated at $37^{\circ} \mathrm{C}$ for $2 \mathrm{~min}$ and incubated with tested compounds for $5 \mathrm{~min}$. Cells were treated with fMLP $(100 \mathrm{nM}) / \mathrm{CB}(0.5 \mu \mathrm{g} / \mathrm{mL})$, and the changes in absorbance at $405 \mathrm{~nm}$ were detected constantly in order to measure elastase release. The results were displayed as the percent of elastase release in the fMLP/CB-activated, drug-free control system.

\subsubsection{Statistical Analysis}

Results are represented as mean \pm SEM, and comparisons were done by applying student's $t$-test. A probability of 0.05 or less was deemed significant. The software SigmaPlot was employed for the statistical analysis.

\section{Conclusions}

Fifteen compounds, including a new aporphine, 3-hydroxyhernandonine (1), and a new lignin, 4'-O-demethyl-7-O-methyldehydropodophyllotoxin (2), were isolated from the resinous wood of the root wood of H. nymphaeifolia. The structures of these isolates were elucidated according to spectroscopic data. Granule proteases (e.g., cathepsin G, elastase) and reactive oxygen species (ROS) [e.g., hydrogen peroxide, superoxide anion $\left(\mathrm{O}_{2}{ }^{\bullet-}\right)$ ] generated by human neutrophils gave rise to the pathogenesis of inflammatory diseases. The effects of the isolated compounds on proinflammatory responses were assessed by inhibiting fMLP/CB-induced elastase release and $\mathrm{O}_{2}{ }^{--}$generation by neutrophils. The results of anti-inflammatory assays reveal that compounds 1-7 and $\mathbf{1 1}$ can obviously inhibit fMLP-induced elastase release and/or $\mathrm{O}_{2}{ }^{\bullet-}$ generation. Oxohernangerine (5) and 3-hydroxyhernandonine (1) were the most effective among the isolated compounds, with $\mathrm{IC}_{50}$ values of $2.65 \pm 0.97$ and $3.93 \pm 0.48 \mu \mathrm{g} / \mathrm{mL}$, respectively, against fMLP-induced $\mathrm{O}_{2}{ }^{\bullet-}$ generation and elastase release. Our research indicates $H$. nymphaeifolia and its isolated compounds (especially 1-7 and 11) are worth further study and may be expectantly developed as candidates for the prevention or treatment of diverse inflammatory diseases.

Supplementary Materials: Supplementary materials are available online, Figures S1-S8: MS, 1D, and 2D-NMR spectra for 3-hydroxyhernandonine (1), Figures S9-S16: MS, 1D, and 2D-NMR spectra for 4'-O-demethyl-7-O-methyldehydropodophyllotoxin (2). 
Author Contributions: C.-Y.W. and J.-J.C. performed the isolation and structure elucidation of the constituents and manuscript writing. C.-Y.W., S.-W.W., J.-W.Y., T.-L.H., M.-J.C., P.-J.S., T.-H.C., and J.-J.C. conducted the bioassay and analyzed the data. J.-J.C. planned, designed, and organized all of the research of this study and the preparation of the manuscript. All authors read and approved the final version of the manuscript.

Acknowledgments: This research was supported by grants from the Ministry of Science and Technology, Taiwan (No. MOST 106-2320-B-010-033-MY3 and MOST 105-2320-B-010-040), awarded to J.-J. Chen. This work was also supported by the grants from Chang Gung Memorial Hospital (CMRPD1B0281 3, CMRPF1D0442 3, CMRPF 1F0011 3, CMRPF1F0061 3 and BMRP450). We are grateful to Ih-Sheng Chen for unselfishly providing us with plant material (root wood of H. nymphaeifolia).

Conflicts of Interest: The authors declare no conflict of interest.

\section{References}

1. Yang, Y.P.; Lu, S.Y. Hernandiaceae. In Flora of Taiwan, 2nd ed.; Editorial Committee of the Flora of Taiwan: Taipei, Taiwan, 1996; Volume 2, pp. 500-503. ISBN 957-9019-52-5.

2. Kan, W.S. Manual of Medicinal Plants in Taiwan; National Research Institute of Chinese Medicine: Taipei, Taiwan, 1970; pp. 178-179.

3. Chen, J.J.; Tsai, I.L.; Ishikawa, T.; Wang, C.J.; Chen, I.S. Alkaloids from trunk bark of Hernandia nymphaeifolia. Phytochemistry 1996, 42, 1479-1484. [CrossRef]

4. Chen, J.J.; Ishikawa, T.; Duh, C.Y.; Tsai, I.L.; Chen, I.S. New dimeric aporphine alkaloids and cytotoxic constituents of Hernandia nymphaeifolia. Planta Med. 1996, 62, 528-533. [CrossRef] [PubMed]

5. Chen, I.S.; Chen, J.J.; Duh, C.Y.; Tsai, I.L.; Chang, C.T. New aporphine alkaloids and cytotoxic constituents of Hernandia nymphaeifolia. Planta Med. 1997, 63, 154-157. [CrossRef] [PubMed]

6. Chen, J.J.; Chang, Y.L.; Teng, C.M.; Chen, I.S. Vasorelaxing and antioxidant constituents from Hernandia nymphaeifolia. Planta Med. 2001, 67, 593-598. [CrossRef] [PubMed]

7. Chen, J.J.; Chang, Y.L.; Teng, C.M.; Chen, I.S. Anti-platelet aggregation alkaloids and lignans from Hernandia nymphaeifolia. Planta Med. 2000, 66, 251-256. [CrossRef] [PubMed]

8. Chen, I.S.; Chen, J.J.; Duh, C.Y.; Tsai, I.L. New cytotoxic lignans from Formosan Hernandia nymphaeifolia. Phytochemistry 1997, 45, 991-996. [CrossRef]

9. Ennis, M. Neutrophils in asthma pathophysiology. Curr. Allergy Asthma Rep. 2003, 3, 159-165. [CrossRef] [PubMed]

10. Borregaard, N. The human neutrophil. Function and dysfunction. Eur. J. Haematol. 1998, 41, 401-413. [CrossRef]

11. Witko-Sarsat, V.; Rieu, P.; Descamps-Latscha, B.; Lesavre, P.; Halbwachs-Mecarelli, L. Neutrophils: Molecules, functions and pathophysiological aspects. Lab. Inverstig. 2000, 80, 617-653. [CrossRef]

12. Roos, D.; van Bruggen, R.; Meischl, C. Oxidative killing of microbes by neutrophils. Microbes Infect. 2003, 5, 1307-1315. [CrossRef] [PubMed]

13. Furukawa, H.; Ueda, F.; Ito, M.; Ishii, H.; Hagniwa, J. Alkaloids of Hernandia ovigera. IV. Constituents of Hernandia ovigera collected in the Bonin Islands. Yakugaku Zasshi 1972, 92, 150-154. [CrossRef] [PubMed]

14. Yang, T.H.; Liu, S.C.; Lin, T.S.; Yang, L.M. Studies on the constituents of the root-bark of Hernandia ovigera L. III. J. Chin. Chem. Soc. 1976, 23, 29-34. [CrossRef]

15. Atta-ur-Rahman; Ashraf, M.; Choudhary, M.I.; Habib-ur-Rehman; Kazmi, M.H. Antifungal aryltetralin lignans from leaves of Podophyllum hexandrum. Phytochemistry 1995, 40, 427-431. [CrossRef]

16. Orito, K.; Uchiito, S.; Satoh, Y.; Tatsuzawa, T.; Harada, R.; Tokuda, M. Aryl radical cyclizations of 1-(2'-bromobenzyl) isoquinolines with $\mathrm{AIBN}^{\prime} \mathrm{Bu}_{3} \mathrm{SnH}$ : Formation of aporphines and indolo[2,1-a]isoquino-lines. Org. Lett. 2000, 2, 307-310. [CrossRef] [PubMed]

17. Chen, J.J.; Tsai, I.L.; Chen, I.S. New oxoaporphine alkaloids from Hernandia nymphaeifolia. J. Nat. Prod. 1996, 59, 156-158. [CrossRef]

18. Kametani, T.; Nitadori, R.; Terasawa, H.; Takahashi, K.; Ihara, M.; Fukumoto, K. Studies on the syntheses of heterocyclic compounds-DCXCIII: A total synthesis of atheroline by photolysis. Tetrahedron 1977, 33, 1069-1071. [CrossRef]

19. Yamaguchi, H.; Arimoto, M.; Yamamoto, K.; Numata, A. Studies on the constituents of the seeds of Hernandia ovigera L. Yakugaku Zasshi 1979, 99, 674-677. [CrossRef] [PubMed] 
20. Tanoguchi, M.; Arimoto, M.; Saika, H.; Yamaguchi, H. Studies on the constituents of the seeds of Hernandia ovigera L. VI. Isolation and structural determination of three lignans. Chem. Pharm. Bull. 1987, 35, 4162-4168. [CrossRef]

21. Ito, C.; Matsui, T.; Wu, T.S.; Furukawa, H. Isolation of 6,7-demethyl-enedesoxypodophyllotoxin from Hernandia ovigera. Chem. Pharm. Bull. 1992, 40, 1318-1321. [CrossRef]

22. Chen, C.Y.; Wang, Y.D.; Wang, H.M. Chemical constituents from the roots of Synsepalum dulcificum. Chem. Nat. Compd. 2010, 46, 46-448. [CrossRef]

23. Chen, C.Y.; Chang, F.R.; Wu, Y.C. The constituents from the stems of Annona cherimola. J. Chin. Chem. Soc. 1997, 44, 313-319. [CrossRef]

24. Sun, X.B.; Zhao, P.H.; Xu, Y.J.; Sun, L.M.; Cao, M.A.; Yuan, C.S. Chemical constituents from the roots of Polygonum bistorta. Chem. Nat. Compd. 2007, 43, 563-566. [CrossRef]

25. Ayyad, S.N. A new cytotoxic stigmastane steroid from Pistia stratiotes. Pharmazie 2002, 57, 212-214. [PubMed]

26. Chen, C.H.; Hwang, T.L.; Chen, L.C.; Chang, T.H.; Wei, C.S.; Chen, J.J. Isoflavones and anti-inflammatory constituents from the fruits of Psoralea corylifolia. Phytochemistry 2017, 143, 186-193. [CrossRef] [PubMed]

27. Boyum, A. Isolation of mononuclear cells and granulocytes from human blood. Isolation of monuclear cells by one centrifugation, and of granulocytes by combining centrifugation and sedimentation at $1 \mathrm{~g}$. Scand. J. Clin. Lab. Inverstig. 1968, 97, 77-89.

28. Jauregui, H.O.; Hayner, N.T.; Driscoll, J.L.; Williams-Holland, R.; Lipsky, M.H.; Galletti, P.M. Trypan blue dye uptake and lactate dehydrogenase in adult rat hepatocytes-freshly isolated cells, cell suspensions, and primary monolayer cultures. In Vitro 1981, 17, 1100-1110. [CrossRef] [PubMed]

29. Babior, B.M.; Kipnes, R.S.; Curnutte, J.T. Biological defense mechanisms. The production by leukocytes of superoxide, a potential bactericidal agent. J. Clin. Inverstig. 1973, 52, 741-744. [CrossRef] [PubMed]

30. Hwang, T.L.; Leu, Y.L.; Kao, S.H.; Tang, M.C.; Chang, H.L. Viscolin, a new chalcone from Viscum coloratum, inhibits human neutrophil superoxide anion and elastase release via a cAMP-dependent pathway. Free Radic. Biol. Med. 2006, 41, 1433-1441. [CrossRef] [PubMed]

31. Chen, J.J.; Ting, C.W.; Wu, Y.C.; Hwang, T.L.; Cheng, M.J.; Sung, P.J.; Wang, T.C.; Chen, J.F. New labdane-type diterpenoids and anti-inflammatory constituents from Hedychium coronarium. Int. J. Mol. Sci. 2013, 14, 13063-13077. [CrossRef] [PubMed]

Sample Availability: Samples of the compounds are available from the authors.

(C) 2018 by the authors. Licensee MDPI, Basel, Switzerland. This article is an open access article distributed under the terms and conditions of the Creative Commons Attribution (CC BY) license (http://creativecommons.org/licenses/by/4.0/). 